\title{
Sentidos do trabalho e imaginário organizacional em um Centro de Atenção Psicossocial - CAPS*
}

\author{
Vinicius Carvalho de Vasconcellos ${ }^{1}$ \\ Creuza da Silva Azevedo
}

VASCONCELLOS, V.C.; AZEVEDO, C.S. The meanings of work and the organizational imaginary in a psychosocial care center (PCC). Interface - Comunic., Saude, Educ., v.14, n.34, p.563-76, jul./set. 2010.

This study examined the imaginary and affective elements of subjective professional-work bonding within the current context of the field of mental health. Using the theoretical framework of the French school of psychosociology, the analysis focused on the meanings that work takes on; organizational imaginary; and professionals' experience of pleasure/ suffering. The empirical material for the investigation was extracted from a field study carried out in a psychosocial care center in the municipality of Rio de Janeiro, Brazil. This analysis found new meanings for attendance, packaged as an imaginary of transformation of care, thereby inspiring pleasure in the work. On the other hand, the challenges of the transformation proposal, the adversities in material support, the seriousness of the cases and the scarce social value of the work give rise to a distressing experience. Influenced by these elements, the bonding to the work and the attendance itself are seated in a fragile balance.

Keywords: Mental health. Health care reform. Work.
Este trabalho investigou os elementos imaginários e afetivos do vínculo subjetivo profissional-trabalho no atual contexto do campo da Saúde Mental. Valendo-se do referencial teórico da psicossociologia francesa, a análise centrou-se nos sentidos assumidos pelo trabalho, no imaginário organizacional e na experiência de prazer/sofrimento dos profissionais. A investigação extraiu seu material empírico de uma pesquisa de campo realizada em um Centro de Atenção Psicossocial do município do Rio de Janeiro, Brasil. Nesta análise detectaram-se novos sentidos para a assistência embalados por um imaginário de transformação do cuidado, inspirando prazer no trabalho. Por outro lado, os desafios da proposta de transformação, as adversidades no suporte material, a gravidade dos casos e a escassa valorização social do trabalho favorecem uma experiência de sofrimento. Influenciados por esses elementos, o vínculo com o trabalho e a própria assistência assentamse em um frágil equilíbrio.

Palavras-chave: Saúde mental. Reforma dos serviços de saúde. Trabalho.

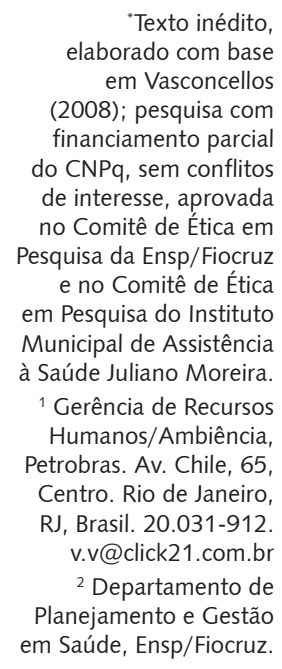

Interface comunicaçĀo SAÚdE EdUCAÇÃO 


\section{Introdução}

A história da psiquiatria moderna teve, no modelo manicomial, sua principal referência desde o final do século XVIII. A partir do contexto histórico de sua emergência, este modelo apoiou-se em determinadas premissas, tais como: o isolamento social dos loucos, a internação em instituições totais, o tratamento moral, o padrão disciplinar da assistência e a exclusividade do discurso médico na condução dos casos. Em última análise, esta linha de tratamento acoplava-se tanto a um ideal de cura quanto à necessidade de "proteção" da sociedade diante da periculosidade, da anomia e da bizarrice que o louco personificava (Desviat, 1999; Amarante, 1996; Pitta, 1996).

Ao sabor da dialética inerente ao processo histórico, tal modelo não passou indene às mudanças políticas, sociais e econômicas dos meados do século XX, emergindo, assim, um período de questionamento. O esforço de mapeamento histórico dos motivos que impulsionaram tais críticas é frequente nas publicações da área de Saúde Mental, assim como a descrição, análise e comparação das propostas de reforma psiquiátrica emergentes em vários países no mundo (Melman, 2001; Desviat, 1999; Amarante, 1995).

Tais iniciativas começaram a repercutir mais acintosamente no Brasil no final da década de 1970 e início da década de 1980. Entrementes, em meio à efervescência pela redemocratização do país e a situação caótica dos hospitais psiquiátricos, os profissionais da área aglutinaram-se em torno de uma ampla teia de contestações, que incluía, em seu bojo: o combate à excessiva privatização da assistência, críticas ao modelo hospitalocêntrico e manicomial, e reivindicações trabalhistas, dando corpo à reforma psiquiátrica brasileira (Amarante, 1995; Bezerra Júnior, 1994; Delgado, 1992).

Desde então, o campo da Saúde Mental no Brasil vem passando por intensas modificações, incluindo grandes avanços na formulação de políticas públicas, na produção teórica e na própria assistência perpetrada pelos profissionais. Imiscuído nessa nova configuração, o próprio vínculo subjetivo dos profissionais com o seu trabalho queda-se sujeito a modificações.

Considerando que a prestação da assistência é influenciada por tal vínculo, o objetivo deste artigo é investigar os matizes que este adquire na atual contextura da Saúde Mental e da reforma psiquiátrica brasileira, especialmente no que toca aos sentidos e ao imaginário organizacional (Enriquez, 1994a) atrelados às práticas assistenciais e às experiências de prazer e de sofrimento existentes no trabalho. Para a consecução desta empresa, este vínculo é apreendido à luz da leitura organizacional da psicossociologia francesa contemporânea, particularmente por meio da perspectiva de Eugène Enriquez, e do estudo da dinâmica prazer-sofrimento psíquico presente na obra de Christophe Dejours. Esse arcabouço fornece lentes que facultam pesquisar o contexto intersubjetivo nos serviços de saúde, esforço que vem adquirindo espaço nas publicações da área da Saúde Pública (Sá, Carreteiro, Fernandes, 2008; Onocko Campos, 2005; Azevedo, 2002; Azevedo, Braga Neto, Sá, 2002).

Os resultados empíricos que serão apresentados adiante advêm de uma pesquisa (Vasconcellos, 2008) que buscou compreender a relação entre a dinâmica intersubjetiva do trabalho em Saúde Mental e três macrocenários que a envolvem: a sociedade contemporânea, o Sistema Único de Saúde (SUS) e a reforma psiquiátrica brasileira.

\section{Imaginário organizacional e a dinâmica prazer-sofrimento no trabalho}

A psicossociologia francesa contemporânea tem como campo precípuo de estudo o cotidiano e a intersubjetividade dos grupos, organizações e comunidades, e assume que os sujeitos se ligam ao seu trabalho e às organizações não apenas por vínculos materiais, mas, sobretudo, por elos simbólicos, imaginários e afetivos.

Ao se debruçar no estudo das organizações, Enriquez destaca o papel do imaginário, entendido aqui como "uma certa maneira de representar aquilo que somos, aquilo que queremos vir a ser, aquilo que queremos fazer e em que tipo de sociedade e de organização desejamos intervir" (Enriquez, 1994a, p.57). O sistema imaginário é povoado por desejos, imagens e representações psíquicas compartilhadas por membros de um grupo/organização, sendo traspassado por processos inconscientes e estando intimamente ligado ao sistema simbólico (conjunto de valores e mitos), 
aspectos que funcionam como balizadores da atuação dos indivíduos, produzindo sentido para suas ações (Enriquez, 1997). O investimento psíquico dos indivíduos em um determinado imaginário coletivo embasa a constituição do grupo e favorece a efetiva realização de um projeto comum (Enriquez, 1994a).

O imaginário dá sustentação às práticas sociais (Takeuti, 2002) e, também, aos projetos a construir, sendo assim ponto de partida para os sentidos e as significações compartilhadas por um grupo social (Freitas, 2000). No marco da psicossociologia francesa, estes sentidos estão inseridos em um processo dinâmico e intersubjetivo que reside na base organizações (Lévy, 2001), remetendo a um vivido em permanente construção e traduzindo significações - muitas vezes contraditórias - para o trabalho (Araújo, 2002). Deste modo, a análise do vínculo do profissional com o trabalho, neste artigo, centrase então em desvelar os sentidos construídos para a atuação profissional e analisar o imaginário organizacional que os embasa.

Adicionalmente, a análise contempla também a dinâmica prazer-sofrimento, utilizando, neste caso, a leitura de Dejours. Dentro deste veio teórico, a experiência de sofrimento no trabalho é vislumbrada como uma "vivência subjetiva intermediária entre doença mental descompensada e o conforto (bem-estar) psíquico" (Dejours, Abdoucheli, 1994, p.127). O autor advoga a existência de formas de vivenciar o trabalho que são mais favoráveis do que outras na negociação da superação desse sofrimento, de maneira que é possível aspirar à transformação de uma parte do sofrimento em prazer. Tal transformação ocorre, sobretudo, quando o indivíduo é capaz de doar sentido à sua atividade e sentir-se reconhecido na sua realização, posto que o reconhecimento assume a forma de uma retribuição simbólica pelo esforço despendido no trabalho (Dejours, 2004a, 1996). É no reconhecimento que entra o papel do outro, operando na própria constituição do elo existente entre o sujeito e seu trabalho: "Se há prazer no trabalho [...] este prazer só pode advir do ganho obtido no trabalho, justamente no registro da construção da identidade e da realização de si mesmo [...] A identidade só pode ser conferida pelo olhar do outro" (Dejours, 2004b, p.213).

$\mathrm{Na}$ costura teórica entre a psicossociologia francesa e a abordagem de Dejours, o estudo do vínculo subjetivo do profissional com o trabalho passa a privilegiar os sentidos dados ao trabalho e o imaginário organizacional subjacente, bem como a ligação destes com a dinâmica prazer-sofrimento emergente na atuação profissional em Saúde Mental.

\section{O campo da saúde mental e as possibilidades do vínculo subjetivo com o trabalho}

A abordagem aqui desenvolvida da relação profissional-trabalho na Saúde Mental brasileira mostra-se especialmente pertinente em função das alterações vivenciadas por esse campo nos últimos decênios. Protagonista dessa cena, a reforma psiquiátrica apresentou-se como uma linha de fuga diante do modelo hospitalocêntrico/manicomial, almejando uma reformulação nas formas de cuidado. Ainda que esse processo não tenha surgido como um monólito e esteja trespassado por dissonâncias entre suas correntes de pensamento (Bezerra Júnior, 1999, 1994), tal dissenso não escamoteia a consolidação de um movimento capaz de propor uma nova forma ao quadro assistencial.

No que se refere à constituição de novos serviços, a reforma ganhou expressão no advento de diferentes dispositivos, dentre os quais se destacam os CAPS, serviços alçados pelas políticas públicas à condição de organizadores da nova rede de Saúde Mental. Estes contam com a presença obrigatória de equipe multidisciplinar e têm a missão de prover atendimento clínico e psicossocial a pessoas com transtornos mentais severos e persistentes, visando a substituir o modelo hospitalocêntrico e evitar internações (Brasil, 2004).

Para além da criação de novos serviços, um modo apropriado para expor as nuanças da reforma psiquiátrica reside em estudar seus impactos nas práticas assistenciais e no vínculo do profissional com seu trabalho. Neste contexto, cumpre resgatar a discussão travada, no seio da reforma brasileira, sobre a atuação profissional, discussão esta assaz marcada pela experiência da reforma psiquiátrica italiana. Basaglia (1985), ao criticar o modelo manicomial, ressaltara que os profissionais da assistência amiúde perfaziam um papel de administradores e concessionários de uma violência técnica, fundada em larga medida na radicalização da assimetria entre o poder do profissional e do usuário. De acordo com essa 
leitura, os técnicos - respaldados por seu saber/poder e pelo mandato social e legal - atuavam como controladores institucionais da loucura.

Essas críticas ecoaram ruidosamente nos profissionais que se envolveram na implantação da reforma psiquiátrica brasileira, que passaram a refletir sobre as práticas de Saúde Mental, a relação com os usuários do serviço, os sentidos de seu trabalho, enfim, sobre sua própria atuação profissional. Em um panorama das recentes publicações da literatura, cabe salientar que alguns autores, ainda que com objetivos e desenhos teórico-metodológicos distintos dos propostos aqui, ressaltaram inserções profissionais encerradas no espírito da reforma. Desta maneira, tais pesquisadores revelam um cuidado alicerçado na reflexão e na experimentação de relações interpessoais mais dialógicas (Nunes et al., 2008), atestando também a existência de um trabalho assistencial como uma práxis que busca a transformação social (Honorato, Pinheiro, 2008).

Contudo, outras pesquisas, mesmo reconhecendo avanços substanciais, observaram a redução da reforma à dimensão técnico-assistencial, esvaziando assim a dimensão política e conceitual (Bueno, Caponi, 2009), além de trazer à baila a persistência de representações sociais típicas da lógica manicomial (Leão, Barros, 2008) ou, ainda, a manutenção dos "desejos de manicômios" (controle, normatização e fixidez) nos profissionais (Alverga, Dimenstein, 2006). Nesta linha, atesta-se a necessidade de contínua autorreflexão e elaboração psíquica dos profissionais como forma de combater os insidiosos "manicômios mentais" internalizados no cotidiano do trabalho (Bezerra Júnior, 2007).

A partir dessa aparente contradição entre os estudos, este artigo legitima-se na tentativa de compreender esse momento de transição, entre os modelos assistenciais, por meio dos sentidos, do imaginário e das experiências de prazer e sofrimento presentes na realização do trabalho em Saúde Mental, fornecendo mais subsídios para se compreenderem as possibilidades de reformulação no cuidado.

\section{Método}

A abordagem qualitativa, entendida aqui como "aquela capaz de incorporar a questão do significado e da intencionalidade como inerentes aos atos, às relações e às estruturas sociais" (Minayo, 1999, p.10), pautou a consecução deste estudo, sendo escolhida em função do objetivo da pesquisa e de seu marco teórico. Mais especificamente, a pesquisa em questão delineou-se como estudo de caso, valendo-se, como universo de investigação, do CAPS Arthur Bispo do Rosário, serviço que compõe a rede de Saúde Mental do município do Rio de Janeiro.

A pesquisa de campo foi realizada no segundo semestre de 2007 e, no total, foram realizadas, aproximadamente, vinte visitas ao CAPS. Duas estratégias foram utilizadas no estudo empírico: observação participante e entrevistas. A observação participante investigou a atuação dos profissionais no fluxo de usuários, no brechó do serviço, na assembleia de usuários, no grupo de referência e na reunião de equipe/supervisão, sendo acompanhada por um diário de campo, no qual foram transcritas as percepções relativas ao campo estudado.

As entrevistas foram individuais e semiestruturadas, sendo realizadas no próprio local de trabalho e com duração média de uma hora. Foram entrevistados profissionais de nível superior e de nível médio, oriundos de diferentes formações profissionais. A seleção dos entrevistados respeitou dois critérios: estar envolvido diretamente nas práticas assistenciais e trabalhar há, pelo menos, um ano no serviço. Salvaguardadas as condições de seleção dos participantes assinaladas acima, o serviço dispunha de 11 profissionais elegíveis para a entrevista, de sorte que, ao cabo da pesquisa de campo, oito profissionais foram entrevistados. Além desses profissionais, dois novos informantes foram incluídos no conjunto de entrevistas: um membro do Centro de Estudos do Instituto Municipal de Assistência Juliano Moreira (IMASJM), referência para o serviço estudado, e a primeira coordenadora do CAPS. Essas inclusões justificam-se tendo em vista que ambos, ao contrário dos demais entrevistados, testemunharam os primeiros passos do serviço.

Partindo do referencial teórico, duas grandes categorias de análise foram privilegiadas na "escuta" do empírico: a primeira perscrutava os sentidos que surgiram entremeados ao exercício do trabalho, especialmente no que tange às práticas assistenciais e à relação dos profissionais com os usuários. 
Por meio dessa análise, tornou-se possível delinear o imaginário que embasava os próprios sentidos assumidos pelo trabalho, tendo em vista que o imaginário serve de ponto de partida para estes; a segunda categoria explorava, à luz desses sentidos e do imaginário, a ligação afetiva (prazer e sofrimento) entrelaçada ao exercício profissional. Tanto em um caso quanto no outro, o processo de reforma psiquiátrica e seus possíveis efeitos sobre o trabalho entraram como pano de fundo para a formulação das questões.

A análise do material empírico, assim como todo o processo de pesquisa, centrou-se na abordagem psicossociológica, em especial na perspectiva clínica (Lévy, 2001), unindo-se a outros trabalhos realizados no campo da Saúde Pública (Sá, Carreteiro, Fernandes, 2008; Azevedo, Fernandes, Carreteiro, 2007). O posicionamento clínico se define como uma "demarché de compreensão daquilo que faz a singularidade radical de uma situação, de um problema, ou de um mal-estar vivido por determinados grupos ou pessoa" (Lévy, 2001, p.23). Essa perspectiva, ao estudar o discurso, traz o sofrimento e a questão da produção de sentido para o centro da análise (Sá, 2005).

Com efeito, a situação de entrevista, nesta perspectiva, é vista como uma forma de impelir o entrevistado a construir uma narrativa e acaba lançando-o na reflexão sobre os sentidos de experiência laboral. No caso das organizações, as entrevistas expressam não só os sentidos e os valores do entrevistado em sua individualidade, mas o colocam também na condição de porta-voz (Pichon-Rivière, 1983) daquela formação social e de sua constelação de elementos imaginários e simbólicos:

Uma organização social se desenvolve, com efeito, em todos os planos, interconectados, da vida dos indivíduos e dos grupos. Ela diz respeito aos atos concretos, ao trabalho [...]; traduzse nas interações que homens e mulheres fazem entre si, com seu corpo e seus sentidos, na alegria ou no sofrimento, sempre na angústia, e nos desejos que sentem nesta experiência compartilhada [...] Num plano mais geral, o ponto de vista clínico permite apreender o conjunto desses processos como o lugar onde se efetua a conjunção entre a história de grupos e coletividades e a dos indivíduos que os constituem. (Lévy, 2001, p.14)

O projeto de pesquisa foi aprovado pelos Comitês de Ética em Pesquisa da Escola Nacional de Saúde Pública/Fiocruz e do Instituto Municipal de Assistência à Saúde Juliano Moreira. Sua realização ocorreu em conformidade com os princípios éticos e condições para pesquisas envolvendo seres humanos estabelecidos na Declaração de Helsinki (1989) e na Resolução n. 196/96 do Conselho Nacional de Saúde.

\section{Resultados e discussão}

\section{Os sentidos do trabalho e o imaginário organizacional no CAPS Bispo do Rosário}

O CAPS Bispo do Rosário situa-se no Complexo Juliano Moreira, zona oeste da cidade do Rio de Janeiro. Este complexo agrega atualmente vários serviços de Saúde Mental, incluindo antigos pavilhões hospitalares que são resquícios da antiga Colônia Juliano Moreira, instituição que foi um dos mais importantes hospitais psiquiátricos da cidade. Por se localizar nas terras do Complexo Juliano Moreira, esse CAPS mostra certa singularidade diante de seus pares, posto que a maioria dos CAPS está distante de estruturas hospitalares e visceralmente inserida no território. Apesar dessa idiossincrasia, a assistência do CAPS Bispo espelha o modelo prescrito pelas políticas públicas do setor.

Na pesquisa de campo, as alusões à reforma psiquiátrica apareceram de modo recorrente quando os profissionais eram instigados a falar sobre seu trabalho. Assim, um profissional, ao ser perguntado sobre os sentidos de trabalhar naquele serviço, responde de pronto que

"significa trabalhar em um serviço de ponta da reforma psiquiátrica, uma instituição alternativa que é de extrema importância para que se possa substituir o modelo asilar". (profissional A) 
Na mesma linha de diferenciação do modelo asilar/manicomial, os relatos apontam que "O CAPS dá um sentido de progresso e sucesso para esse movimento de transformação da assistência e de deixar para trás essa assistência que se fazia aqui antigamente". (profissional B)

ou ainda que

"O CAPS vem com essa intenção de ser substitutivo desse modelo (asilar/manicomial) e isso me orgulha muito". (profissional A)

Tais falas refletem o afã de se afastar/substituir as práticas manicomiais, movimento este embalado no próprio discurso da reforma. Este primeiro sentido para o trabalho surge revestido de importância e orgulho, apontando para a existência de investimento psíquico e identificação com as propostas da reforma, e para a capacidade desta em despertar afetos positivos, reforçando achados de outras pesquisas (Nardi, Ramminger, 2007). Conforme exposto anteriormente, para a psicossociologia francesa, tais processos são fundamentais para o compartilhamento de um projeto social ou organizacional, como no caso da reforma psiquiátrica.

O apelo em prol da superação do modelo manicomial e da realização de um trabalho encerrado no espírito da reforma encontra, na reunião de equipe/supervisão, um locus privilegiado de manifestação:

"As discussões da reforma aparecem mais nas reuniões de equipe/supervisões e a gente tenta adequar a teoria ao nosso cotidiano de trabalho". (profissional C)

Uma das facetas mais relevantes desse encontro reside na discussão sobre a atuação da equipe técnica, esforço que se arvora na tentativa de se ampliarem as possibilidades assistenciais:

"Qualquer coisa que acontece nos casos nós discutimos na reunião de equipe e a supervisora parece que tem sempre uma questão em torno do que está sendo discutido. E que faz a gente pensar: peraí, de fato, a gente devia estar dando conta disso". (profissional D)

A reunião de equipe/supervisão, ao resgatar as discussões da reforma e fomentar esse apelo reflexivo, parece cumprir a função de alimentar e difundir o sentido de substituição do modelo manicomial. Tal encontro delineia-se, assim, como um mecanismo institucional capaz de aglutinar os profissionais em torno desse eixo de cuidado, favorecendo o investimento psíquico nas propostas de mudança da reforma psiquiátrica. Esse momento coletivo parece propiciar ao grupo o papel de fiador de um projeto que o transcende (Enriquez, 1997).

Como forma de desnudar as nuances assumidas por este primeiro sentido do trabalho (substituição/superação das práticas manicomiais), foi mister apreender como este se desdobrava em outros sentidos. Desse modo, a maioria dos entrevistados, ao se reportar a este processo de renovação, o fez calcada em dois grandes eixos: os objetivos almejados pelo trabalho em Saúde Mental e a relação profissional-usuário. No que tange ao que os profissionais aspiram de suas práticas, as falas pontuam que:

“O possível de se esperar (da atuação profissional) é que o usuário com transtorno mental possa seguir o curso de sua vida de uma maneira menos sofrida, lidar melhor com as situações que a vida vai the trazendo". (profissional A)

"Simplesmente não é se vai namorar, trabalhar ou ter um milhão de coisas na vida, é ter um lugar na vida. [...] É possível existir, porque tem gente que não existia". (profissional E)

Em realce, despontam como sentidos do exercício profissional: a mitigação do sofrimento psíquico e a busca por novas formas de existência dos usuários. Os trechos, à primeira vista, parecem denunciar 
um tom menos pretensioso na atuação profissional, especialmente se comparado ao ideal de cura do discurso manicomial, vinculado à restituição de um estado de "normalidade". Este ideal soçobrou no discurso e nas práticas observadas, sendo posto de lado pelos participantes. Por outro lado, o segundo trecho deixa transparecer o propósito de se retirarem os usuários do CAPS de seu "nãolugar" social, tarefa que, dada sua complexidade, pode também operar (ainda que na direção oposta) como um ideal (Enriquez, 1997), isto é, um objeto ou objetivo maravilhoso/ admirável porém, concomitantemente, difícil/distante.

Sobre a relação profissional-usuário, cumpre resgatar que o modelo manicomial sustentava-se fortemente na radical diferença de poder entre os dois polos do par assistencial, diferença esta assentada em certas assimetrias: aquele que assiste em oposição ao que é assistido, o douto versus o ignorante e o são contraposto ao louco, onde o primeiro elemento refere-se ao profissional e, o segundo, ao usuário. Essas bases da díade profissional-usuário foram colocadas na berlinda pela reforma psiquiátrica, porquanto essas polarizações, quando levadas ao extremo, dificultam a constituição de um campo intersubjetivo no cuidado. Logo, a necessidade de re-significar os papéis de usuários e profissionais confronta-se necessariamente com as possibilidades e limites de se enfrentarem essas assimetrias. As bases da relação assistencial foram também abordadas pelos entrevistados:

“Eu procuro ter uma relação de respeito acima de tudo, uma relação não-hierarquizada, mesmo sabendo que temos papéis diferentes; em alguns casos até uma relação de amizade". (profissional D)

\footnotetext{
"Nosso papel é de desmistificar a loucura. Muitas coisas que eles fazem são mais lúcidas do que ações de muitos que não se dizem loucos. Quem são os loucos?". (profissional F)
}

\begin{abstract}
"A gente aqui vai ter as mais diversas questões: pessoas loucas, pessoas que furtam, que às vezes usam drogas, que têm questões sexuais importantes. Se a gente tiver preconceito nem pode aparecer no local de serviço. Importante é que essas distâncias entre profissional e usuários não fiquem tão grandes". (profissional C)
\end{abstract}

Esses fragmentos mostram, de diferentes formas, um sentido de aproximação, isto é, a tentativa de reduzir o vão existente entre usuários e profissionais, substituindo a radicalização das assimetrias. Por outro lado, cumpre notar que essa aproximação pode assumir contornos marcantes, como na fala sobre o apagamento da assimetria entre o são e o louco, ou na injunção acerca da ausência de preconceito no serviço. É possível questionar até que ponto a relação assistencial de fato desenvolvese nessas bases ou, mesmo, se esse discurso aparentemente tão avançado não esconderia a própria dificuldade de se vivenciarem as assimetrias.

De todo modo, se afirmar a inexistência de uma relação de poder nesse par pode soar como ingenuidade, o cerne da contenda encontra-se justamente na criação de um solo comum para o cuidado, o que ocorre a partir da construção de novas formas de se vivenciarem as assimetrias e de práticas que reconheçam a condição de sujeito dos usuários, mesmo sabendo da dificuldade inerente a essas tarefas.

Todavia, se essa busca por re-significação na atuação profissional - seja na relação com o usuário ou nos objetivos do trabalho - germinou no material empírico recoberto de importância, sua dificuldade de consecução não se eximiu de aparecer. Essa situação dispõe à mesa uma imagem do trabalho assistencial em Saúde Mental:

"Como é um serviço novo, a exigência do serviço é muito maior do que em outros serviços de Saúde Mental. Você está no front. Essa é uma palavra que a gente usa muito nas reuniões". (profissional F)

Dos fios de significados derivados da metáfora do front, o primeiro desvela um serviço na vanguarda da luta pela difícil renovação do cuidado, ou seja, responsável por carrear o avanço nos limites 
assistenciais. O mesmo profissional expressa que o CAPS figura como "o contrário frente à história da Colônia" (profissional F), instituição cuja trajetória foi sobejamente marcada pela assistência manicomial.

O trabalho representado como front, desta feita, traduz a confrontação com o modelo manicomial, reforçando (e radicalizando) o sentido de substituição inicialmente explicitado. De fato, este sentido adquire maior concretude (isto é, de uma luta ainda viva e em curso) ao se constatar a persistência de elementos manicomiais na assistência, o que foi levantado por alguns entrevistados, em linha com algumas pesquisas citadas na introdução. No exemplo abaixo, um profissional reflete sobre a atuação clínica no CAPS:

"Algumas situações clínicas do CAPS sofriam intervenções que eu nomearia de manicomiais, porque se tinha uma tentação de dar conta de tudo; não dar conta de tudo no sentido que a reforma propõe, mas em um viés manicomial". (profissional E)

A alusão ao front feita pelo profissional $\mathrm{F}$ traduz, similarmente, um cenário permeado por dificuldades, no qual obstáculos se colocam cotidianamente. Neste sentido, o trecho seguinte de sua entrevista menciona problemas materiais e financeiros do trabalho:

"falta investimento profissional e financeiro e isso dificulta todas as práticas. São poucos profissionais para dar conta do serviço e acaba sobrecarregando os que já estão". (profissional F)

Outro profissional complementa:

“Nós sentimos falta de material para trabalhar, de escritório, de higiene, a alimentação é precária". (profissional A)

Na cena assistencial de um front, essas condições desfavoráveis se aliam à ambição transformadora da reforma para condensar um sentido moral assumido pelo trabalho, qual seja, o do sacrifício:

“Estou fazendo algo que quase ninguém quer fazer pelo dinheiro que a gente ganha aqui. É algo que me engrandece muito, acho que eu pude evoluir muito como pessoa aqui dentro. Em poucos trabalhos você consegue isso. [...] Me toca aqui a grandiosidade do trabalho e que às vezes a gente não se dá conta. Meio altruísta, sacrificante". (profissional C)

O sacrificio espelha a doação pessoal em prol de um objetivo muito importante e de difícil consecução, mesmo que as recompensas/condições não estejam à altura do esforço despendido. Tal significação expressa uma forma específica de investimento psíquico no trabalho e, por consequência, na proposta/projeto da reforma, propiciando um processo de idealização que já fora ilustrado acima nos trechos que versam sobre a reformulação nos objetivos do trabalho. A idealização canaliza o desejo e confere a um projeto compartilhado uma "aura" excepcional (ou grandiosa), mobilizando o grupo em torno de sua realização (Enriquez, 1994b).

A partir desta análise, é possível considerar que, subjacente ao trabalho realizado no CAPS, encontra-se um imaginário de transformação da assistência, que desperta uma série de sentidos encadeados, tais como: a confrontação e a superação do modelo (e do imaginário) manicomial, a criação de novas formas de existência para os usuários (com mitigação de sofrimento), e a redução das assimetrias entre os componentes do par assistencial. Em meio à complexidade/importância de tal projeto e das dificuldades, inclusive materiais, que abraçam sua implantação, o imaginário de transformação da assistência assume também uma feição de grandiosidade, o que reveste o exercício profissional com um sentido de sacrifício e enobrece seus artífices. Essa dupla constituição imaginária repercute em outra faceta do vínculo do profissional: a dinâmica prazer-sofrimento. 


\section{A dinâmica prazer-sofrimento na assistência}

O imperativo de concretizar a grandiosa proposta de transformação da reforma acaba remetendo os profissionais ao "olho do furação" (Merhy, 2004), ou seja, a uma situação permeada pelo imenso desafio de mudar práticas de saúde até então hegemônicas. Inserido nesse contexto, o trabalho demanda dos profissionais, como contrapartida, uma exigência psíquica consoante com a magnitude de tal projeto assistencial:

"o profissional começa a se achar superexigido, sobrecarregado, pois a proposta da reforma é muito grandiosa". (profissional E)

A tradução desse imaginário de transformação e grandiosidade na ligação afetiva com o trabalho merece, portanto, uma análise cuidadosa. Em algumas entrevistas, o cotejamento da assistência prestada com as expectativas alimentadas pela proposta reformista parece apontar para um descolamento, de modo que a variável margem que separa o prescrito e o possível pode engendrar o aparecimento de grandes fendas entre esses polos:

“O CAPS não consegue entrar na vida desses pacientes [...] Não digo que não tenha essa intenção, mas isso é até um fardo, é uma responsabilidade muito grande. É até de se questionar se algum dia, algum CAPS, vai conseguir alcançar essa responsabilidade. Eu não tenho a menor dúvida que não". (profissional C)

Antes de ser uma crítica frontal à assistência prestada no CAPS, as palavras desse técnico descortinam o "real" do trabalho (Dejours, Adboucheli, Jayet, 1994), levando-o a questionar as possibilidades do CAPS e seus limites enquanto dispositivo. Nessa fala, o desafiador e grandioso horizonte proposto pela reforma torna-se um peso a ser carregado em função do desfiladeiro entre a proposta e a prática, denotando uma vivência de sofrimento.

Cabe salientar que a falta de investimento profissional e a exiguidade de recursos já assinaladas potencializam essas vivências de sofrimento, visto que surgem como empecilhos para a mudança da assistência, ecoando no trabalho como obstáculos a serem superados. O fragmento abaixo destaca esse quadro de precariedade das condições de trabalho (uma realidade que, no fundo, parece grassar por quase todo SUS) e seu impacto do ponto de vista afetivo:

“tento fazer com que essas dificuldades (nas condições de trabalho) não acarretem um atendimento deficiente, mas não é fácil [...] é um serviço muito intenso até pelo aspecto emocional". (profissional A)

Outra fonte de sofrimento brota das recorrentes falas sobre a gravidade e a complexidade dos casos de psicose, o que desvela a grande incerteza sobre os rumos e resultados do próprio trabalho:

"Aqui se trabalha com uma clientela grave, que a todo o momento traz um impasse. Outros imperativos se impõem, a questão da família, do dinheiro, dos direitos. Então eu acho um exercício muito duro". (profissional E)

"A incerteza surge o tempo todo, desde a frequência dos pacientes, a adesão nas atividades, até o retorno que se tem nas atividades". (profissional D)

“Tem alguma coisa nisso aí que a gente chama de loucura que é estranho, que traz para a gente uma angústia e uma impotência absurda. A gente vê pessoas que a gente estabiliza um tempão, em um dado momento aquilo vai ruir de novo" (profissional E) 
Essa reduzida governabilidade sobre o processo de trabalho, crivada pelo desconhecimento, pela estranheza e pelas incertezas que rondam o cuidado, repercute na ligação dos profissionais com o trabalho. No caso da Saúde Mental, esta incerteza banha toda a cadeia de cuidado e a relação do usuário com o serviço, emprestando certa imprevisibilidade aos resultados da assistência e obstaculizando a obtenção de retorno profissional, o que gera desgaste emocional aos técnicos.

Ainda na questão do sofrimento, a maioria dos entrevistados alude a certa desvalorização social de seu trabalho. Assim, um profissional relata comentários que costuma ouvir sobre sua atividade:

“Têm aqueles que falam: 'Como você suporta isso? Eu não daria para isso de jeito nenhum.' E essa fala às vezes é seguida de 'ainda bem que alguém faz' ou 'para mim não serviria'". (profissional D)

Neste ponto, cumpre recuperar, da introdução do artigo, o papel do reconhecimento na dinâmica prazer-sofrimento no trabalho, especialmente em sua capacidade de transformar sofrimento em prazer (Dejours, 2004a). Na percepção desse entrevistado, o olhar do outro não inspira apreço/ reconhecimento, situação que repercute de forma desfavorável no vínculo com o trabalho, favorecendo o sofrimento.

De outra parte, decerto que o vínculo com o trabalho não finca seus pilares apenas no terreno do sofrimento. Paradoxalmente, o próprio investimento psíquico na proposta da reforma psiquiátrica e no imaginário de transformação e grandiosidade que cerca o trabalho, se pode trazer sobrecarga emocional pela sua ambição, franqueia também, aos técnicos, a possibilidade de positivar sua inserção profissional. Isto é, o investimento na reforma parece conferir, aos profissionais, a vivência de que os mesmos estão inseridos em um projeto legítimo e relevante, apoiando a passagem de parte do sofrimento ao prazer.

Destarte, a grandiosidade de um projeto que, por um lado, se propõe a assistir um segmento da população, em geral, subalternizado, e, por outro, tenciona reformular práticas assistenciais em meio a dificuldades consideráveis, talvez seja capaz de fornecer imaginariamente uma espécie de "recompensa moral" aos profissionais, como expresso em um trecho já citado, no qual o profissional afirma que o trabalho o engrandece e o faz evoluir como pessoa. Essa valorização moral arrogada à assistência pode abrandar a desvalorização social ressaltada antes, especialmente ao se valer de uma imagem de desprendimento no exercício do trabalho.

Em acréscimo, a obtenção de um bom resultado na assistência surge também como outra fonte de prazer, notadamente quando os profissionais identificam êxito na condução de casos difíceis. Tais casos eram citados nas entrevistas quando os técnicos eram indagados sobre as cenas/situações que caracterizavam seu trabalho no CAPS:

\footnotetext{
“Uma cena de um paciente que chegou altamente agressivo, ameaçador e inibidor. [...]. Hoje em dia essa pessoa trabalha com carteira assinada, a vida dele tomou outro rumo e já até saiu do CAPS. Esse foi um caso que marcou muito porque nós vimos como ele chegou e como contribuímos". (profissional F)
}

A insistência nesta linha de relato não trata essencialmente sobre a frequência de bons resultados, mas sobretudo sobre sua capacidade de condensar os sentidos do trabalho, como no exemplo acima, no qual uma nova forma de inserção social e de existência desponta para o usuário. Nestes momentos, o trabalho no CAPS imprime sua marca na subjetividade dos técnicos, pois estes vislumbram a materialização dos sentidos do trabalho e a potência da proposta assistencial. Ocorre, como apontou Dejours (2004b), uma reapropriação do trabalho, que facilita a transformação do sofrimento em prazer, cumprindo uma função psíquica fundamental para sustentar a própria realização do trabalho. 


\section{Considerações finais}

A pesquisa de campo facultou a interpretação de que a transmutação da assistência vem abarcando, além dos planos teórico-conceitual, técnico-assistencial, jurídico-político e sociocultural (Amarante, 1997), o plano imaginário, impulsionando novos sentidos para a assistência.

Neste CAPS, o trabalho parece sustentado por um imaginário de transformação assistencial e de grandiosidade, estando estritamente vinculado ao discurso da reforma psiquiátrica que, por sua vez, afigurou-se como objeto de investimento psíquico por parte dos profissionais. Com efeito, é particularmente interessante notar que esse investimento encontra-se, em algum nível, no contrarrumo da conjuntura social contemporânea, comumente retratada pelo esmaecimento dos ideais partilhados, das fontes de identidades grupais e dos projetos de transformação (Bauman, 2000; Enriquez, 1994b).

A presença do imaginário de transformação, todavia, não garante a plena mudança nas práticas assistenciais, como visto no material empírico. De fato, o abandono dos códigos anteriores e dos "manicômios mentais", que asseguravam um modelo de conduta seguro e estável, traz consigo a necessidade de se mudarem laços de significação vigentes, desencaixe que dificilmente ocorre ex abrupto (Koda, Fernandes, 2007). Dentro desta interpretação, poder-se-ia falar verdadeiramente em um confronto entre diferentes imaginários.

Por ser um serviço instalado em um macrocomplexo hospitalar, mas criado e conduzido na brasa da reforma, o CAPS pesquisado surge como precisa metonímia desta luta e desponta como um locus no qual o atrito entre o passado manicomial e o presente da reforma psiquiátrica irrompe de modo ainda mais estridente.

De toda forma, se essa luta ainda permanece viva no front do Bispo do Rosário, o espírito crítico presente nas reuniões de equipe e novos sentidos para o trabalho são auspiciosos. Tal dinâmica poderia despertar o que Enriquez (1997) denominou por imaginário motor, isto é, uma fantasmática compartilhada capaz de introduzir a diferença no processo de trabalho por meio do questionamento e da criatividade.

Neste cenário, se os eventuais êxitos na relação terapêutica e o imaginário de grandiosidade (pela importância e ambição da proposta reformista) inspiram prazer na realização do trabalho, por outro lado, esse mesmo imaginário de grandiosidade (em função dos complexos desafios envolvidos), as adversidades no suporte material e financeiro, a gravidade e a incerteza dos casos, além da escassa valorização social, podem favorecer uma experiência de sofrimento na atuação profissional. Nesta composição, as dificuldades repousam imaginariamente contrabalanceadas com vivências positivas, de modo que é a existência do equilíbrio precário entre esses elementos que articula a própria viabilidade da assistência.

Neste equilíbrio precário, a valorização e o reconhecimento profissional assumem relevância ainda maior, visto que são capazes de favorecer a transformação do sofrimento em prazer e estão na base da constituição do vínculo subjetivo profissional-trabalho. Deste modo, é imperativo se potencializarem os mecanismos de reconhecimento do trabalhador da Saúde Mental, seja por meio de políticas de recursos humanos mais dignas, de melhores condições de trabalho ou conseguindo maior visibilidade das ações no campo social, o que certamente repercutirá na própria qualidade do trabalho assistencial.

\section{Colaboradores}

Vinícius Carvalho Vasconcellos responsabilizou-se por executar a pesquisa, analisar os resultados e redigir o artigo. Creuza da Silva Azevedo analisou os resultados e revisou o manuscrito. 


\section{Referências}

AMARANTE, P. Loucura, cultura e subjetividade: conceitos e estratégias, percursos e atores da Reforma Psiquiátrica Brasileira. In: FLEURY, S. (Org.). Saúde e democracia: a luta do CEBES. São Paulo: Lemos Editorial, 1997. p.163-85.

O homem e a serpente: outras histórias para a loucura e a psiquiatria. Rio de Janeiro: Fiocruz, 1996.

AMARANTE, P. Loucos pela vida: a trajetória da reforma psiquiátrica no Brasil. Rio de Janeiro: Fiocruz, 1995.

ALVERGA, A.R.; DIMENSTEIN, M.A. reforma psiquiátrica e os desafios na desinstitucionalização da loucura. Interface - Comunic., Saude, Educ., v.10, n.20, p.299-316, 2006.

ARAÚJO, J.N.G. Resenha. Psicol. Rev., v.8, n.11, p.133-5, 2002.

AZEVEDO, C.S. Liderança e processos intersubjetivos em organizações públicas de saúde. Cienc. Saude Colet., v.7, n.2, p.349-61, 2002.

AZEVEDO, C.S.; BRAGA NETO, F.C.; SÁ, M.C. O indivíduo e a mudança nas organizações públicas de saúde: contribuições da psicossociologia. Cad. Saude Publica, v.18, n.1, p.235-47, 2002.

AZEVEDO, C.S.; FERNANDES, M.I.A.; CARRETEIRO, T.C. Sob o domínio da urgência: a prática de diretores de hospitais públicos do Rio de Janeiro, Brasil. Cad. Saude Publica, v.23, n.10, p.2410-20, 2007.

BASAGLIA, F. A instituição negada: relato de um hospital psiquiátrico. Rio de Janeiro: Graal, 1985.

BAUMAN, B. Em busca da política. Rio de Janeiro: Jorge Zahar, 2000.

BEZERRA JÚNIOR, B. Desafios da reforma psiquiátrica no Brasil. Physis, v.17, n.2, p.243-50, 2007.

. A diversidade no campo psiquiátrico: pluralidade ou fragmentação. Cad. IPUB, n.14, p.135-44, 1999.

De médico, de louco e todo mundo um pouco: o campo psiquiátrico no Brasil dos anos 80. In: GUIMARÃES, R.A.W.; TAVARES, R. (Orgs.). Saúde e sociedade no Brasil: anos 80. Rio de Janeiro: Relume-Dumará, 1994. p.171-91.

BRASIL. Ministério da Saúde. Saúde Mental no SUS: os Centros de Atenção Psicossocial. Brasília: Ministério da Saúde, 2004.

BUENO, M.L.; CAPONI, S. A construção do discurso dos sujeitos envolvidos com o processo de reforma psiquiátrica: um estudo sobre o município de Joinville/SC. Interface Comunic., Saude, Educ., v.13, n.28, p.137-50, 2009.

DEJOURS, C. Addendum - da psicopatologia à psicodinâmica do trabalho. In: LANCMAN, S.; SZNELWAR, L.I. (Orgs.). Christophe Dejours: da psicopatologia à psicodinâmica do trabalho. Rio de Janeiro: Fiocruz, 2004a. p.47-104.

Análise psicodinâmica das situações de trabalho e sociologia da linguagem. In: LANCMAN, S.; SZNELWAR, L.I. (Orgs.). Christophe Dejours: da psicopatologia à psicodinâmica do trabalho. Rio de Janeiro: Fiocruz, 2004b. p.197-241.

. Uma nova visão do sofrimento humano nas organizações. In: CHANLAT, J.F. (Org.). $O$ indivíduo na organização: dimensões esquecidas. São Paulo: Atlas, 1996. p.149-73.

DEJOURS, C.; ABDOUCHELI, E.; JAYET, C. Psicodinâmica do trabalho. São Paulo: Atlas, 1994. 
DEJOURS, C.; ABDOUCHELI, E. Itinerário teórico em psicopatologia do trabalho. In: DEJOURS, C.; ABDOUCHELI, E.; JAYET, C. (Orgs.). Psicodinâmica do trabalho. São Paulo: Atlas, 1994. p.119-45.

DELGADO, P.G. As razões da tutela: psiquiatria, justiça e cidadania do louco no Brasil. Rio de Janeiro: Te Corá, 1992.

DESVIAT, M. A reforma psiquiátrica. Rio de Janeiro: Fiocruz, 1999.

ENRIQUEZ, E. A organização em análise. Petrópolis: Vozes, 1997.

ENRIQUEZ, E. O vínculo grupal. In: LÉVY, A. (Org.). Psicossociologia: análise social e intervenção. Petrópolis: Vozes, 1994a. p.56-69.

O papel do sujeito humano na dinâmica social. In: LÉVY, A. (Org.).

Psicossociologia: análise social e intervenção. Petrópolis: Vozes, 1994b. p.25-49.

FREITAS, M.E. A questão do imaginário e a fronteira entre a cultura organizacional e a psicanálise. In: MOTTA, F.P.; FREITAS, M.E. (Orgs.). Vida psíquica e organização. Rio de Janeiro: FGV, 2000. p. 41-73.

HONORATO, C.; PINHEIRO, R. O trabalho do profissional de saúde mental em um processo de desinstitucionalização. Physis, v.18, n.2, p.361-80, 2008.

KODA, M.Y.; FERNANDES, M.I.A. A Reforma Psiquiátrica e a constituição de práticas substitutivas em saúde mental: uma leitura institucional sobre a experiência de um núcleo de atenção psicossocial. Cad. Saude Publica, v.23, n.6, p.455-61, 2007.

LEAO, A.; BARROS, S. As representações sociais dos profissionais de saúde mental acerca do modelo de atenção e as possibilidades de inclusão social. Saude Soc., v.17, n.1, p.95-106, 2008.

LÉVY, A. Ciências clínicas e organizações sociais. Belo Horizonte: Autêntica, 2001.

MELMAN, J. Família e doença mental: repensando a relação entre profissionais de saúde e familiares. São Paulo: Escrituras, 2001.

MERHY, E.E. Os CAPS e seus trabalhadores: no olho do furacão antimanicomial. 2004. Disponível em: <http://www.uff.br/saudecoletiva/professores/merhy/capitulos-08.pdf>. Acesso em: 10 jun. 2009.

MINAYO, M.C.S. O desafio do conhecimento: pesquisa qualitativa em saúde. São Paulo: Hucitec, 1999.

NARDI, H.C.; RAMMINGER, T. Modos de subjetivação dos trabalhadores de saúde mental em tempos de reforma psiquiátrica. Physis, v.17, n.2, p.265-87, 2007.

NUNES, M. et al. A dinâmica do cuidado em saúde mental: signos, significados e práticas de profissionais em um Centro de Assistência Psicossocial em Salvador, Bahia, Brasil. Cad. Saude Publica, v.24, n.1, p.188-96, 2008.

ONOCKO CAMPOS, R. O encontro trabalhador-usuário na atenção à saúde: uma contribuição da narrativa psicanalítica ao tema do sujeito na saúde coletiva. Cienc. Saude Colet., v.10, n.3, p.573-83, 2005.

PICHON-RIVIÈRE, E. O processo grupal. São Paulo: Martins Fontes, 1983.

PITTA, A. Ética e assistência em psiquiatria. In: SILVA FILHO, J.F.; FIGUEIREDO, A.C. (Orgs.). Ética e saúde mental. Rio de Janeiro: Topbooks, 1996. p.103-10.

SÁ, M.C. Em busca de uma porta de saída: os destinos da solidariedade, da cooperação e do cuidado com a vida na porta de entrada de um hospital de emergência. 2005. Tese (Doutorado) - Instituto de Psicologia, Universidade de São Paulo, São Paulo. 2005.

SÁ, M.C.; CARRETEIRO, T.C.; FERNANDES, M.I.A. Limites do cuidado: representações e processos inconscientes sobre a população na porta de entrada de um hospital de emergência. Cad. Saude Publica, v.24, n.6, p.1334-43, 2008. 
TAKEUTI, N.M. No outro lado do espelho: a fratura social e pulsões juvenis. Rio de Janeiro: Relume-Dumara, 2002.

VASCONCELLOS, V.C. A dinâmica do trabalho em Saúde Mental: limites e possibilidades na contemporaneidade e no contexto da Reforma Psiquiátrica brasileira. 2008. Dissertação (Mestrado) - Escola Nacional de Saúde Pública, Fundação Oswaldo Cruz, Rio de janeiro. 2008.

VASCONCELLOS, V.C.; AZEVEDO, C.S. Sentidos del trabajo e imaginario de organización en un Centro de Atención Psico-Social - CAPS. Interface - Comunic., Saude, Educ., v.14, n.34, p.563-76, jul./set. 2010.

Este trabajo ha investigado los elementos imaginarios y afectivos del vínculo subjetivo profesional-trabajo en el actual contexto del campo de Salud Mental. Valiéndose del referencial teórico de la psico-sociología francesa, el análisis se ha centrado en los sentidos asumidos por el trabajo en el imaginario de organización y en la experiencia de placer/ sufrimiento de los profesionales. La investigación extrae su material empírico de una pesquisa de campo realizada en un Centro de Atención Psico-social del municipio de Rio de Janeiro. En este análisis se han destacado nuevos sentidos para la asistencia asociados a un imaginario de transformación del cuidado, inspirando placer en el trabajo. Por otro lado, los desafíos de la propuesta de transformación, las adversidades en el soporte material, la gravedad de los casos y la escasa valoración social del trabajo favorecen una experiencia de sufrimiento. Influenciados por tales elementos, el vínculo con el trabajo y la propia asistencia se apoyan en un frágil equilibrio.

Palabras clave: Salud mental. Reforma de la atención de salud. Trabajo. 